\title{
Substitution of chemical fertilizer nitrogen through Rhizobium inoculation technology
}

\author{
Som Prasad Paudyal" and V.N.P. Gupta** \\ Department of Botany, Trichandra College, Tribhuvan University, Kathmandu, Nepal \\ *E-mail: paudyalsp@yahoo.com \\ **E-mail:vngupta110@gmail.com
}

\begin{abstract}
Nitrogen is one of the most essential elements for plants growth and development. Urea is commonly used as a substitute for chemical nitrogen. Rhizobium inoculation technology for legume crop was evaluated in a number of field experiments comparing with $80 \mathrm{~kg}$ urea per hectare application. The inoculation and urea application trial showed almost similar biomass accumulation, nodule number and nodule dry weight compared to un-inoculated control. The symbiotic effectiveness with inoculated and urea application showed similar results. The inoculant strains isolated locally from Mucuna pruriens (velvet bean) were found suitable for inoculants production. The biotechnology of inoculation can be a promising and cheap alternative of urea for the legume crops.
\end{abstract}

Key words: Legume crops, Biomass, Inoculant, Strains, symbiotic effectiveness, Mucuna pruriens.

DOI: http://dx.doi.org/10.3126/on.v16i1.22121

Manuscript details: Received: 09.05.2018 / Accepted: 02.08.2018

Citation: Paudyal, S.P. and V.N.P. Gupta 2018. Substitution of chemical fertilizer nitrogen through Rhizobium inoculation technology, Our Nature 16(1): 43-47. DOI: http://dx.doi.org/ 10.3126/on.v16i1.22121

Copyright: (C) Paudyal and Gupta 2018. Creative Commons Attribution - Non Commercial 4.0 International License.

\section{Introduction}

The leguminous plants have a unique advantage in agriculture because they possess the potential capability to fix atmospheric nitrogen by establishing symbiotic relationship with root nodule bacterium called Rhizobium. A nodule on the roots of legume plants is the real site of nitrogen fixation. They are induced by compatible Rhizobium species available in the soil. Artificial inoculation with specific rhizobial species to a particular legume in the soil (lower fertility status containing lower levels of nutrient nitrogen) enhances nodulation process and in turn fixes nitrogen required for plants growth and development. This type of practice, as reported in many cases, leads towards the nitrogen independency of the legumes. At the same time soil becomes enriched with nutrient nitrogen by sloughing off of the older nodules or leaching out of fixed nitrogen which gets mixed up with the soil. Tian et al. (2000) experimented on the legume crops and found that the nitrogen uptake of the maize crop is higher following cover crops than after maize or other natural grasses. The different legume cover crops used in their experiments could potentially save 50$100 \mathrm{~kg} \mathrm{~N} / \mathrm{ha}$. The symbiosis between Rhizobium and Bradyrhizobium and legumes are a cheaper and usually more effective agronomic practice for ensuring an adequate supply of $\mathrm{N}$ for legume-based crops and pasture production than the application of fertilizer $\mathrm{N}$. The introduction of legumes into the pastures is seen as the best strategy to improve the nitrogen nutrition of the grasses.

It has been speculated that the non-renewable energy boxes will be emptied after a few decades. When the energy boxes finish up, the present practice of industrial production of $\mathrm{N}$ - 
fertilizer will suffer. Thus, it leads to the scarcity of chemical fertilizer, which in turn, reduces crop productivity. To stop such a disaster, legume Rhizobium bio-technology may be properly modulated to meet the demand of crop production on a sustainable basis.

It is widely accepted that the capacity of nitrogen fixation by a nodulating legume is influenced, at least in two ways by mineral nitrogen in the soil. First, relatively low levels of available nitrate or ammonia may promote the process of nodulation, higher concentration of which almost always suppresses nodulation (Davidson and Robson, 1986; Eaglesham, 1989). Second, the rate of nitrogen fixation by an actively growing and well nodulated legume is always suppressed by $\mathrm{NO}_{3}{ }^{-}$ions (Herdina and Silsbury, 1989; Xia et al., 2017). It is being established that soil nitrate inhibits root infection (Abdel-Wahab et al., 1996), nodule development (Atkins et al., 1984; Ismande, 1986) and nitrogenase activity (Purcell and Sinclair, 1990; Sanginga et al., 1996; Arreseigor et al., 1997).

Rhizobial inoculant is relatively less expensive. It would take at least US $\$ 87$ worth of urea to produce a soybean yield comparable to that possible only US \$ 3 worth of inoculants (Somasegaran et al., 1992). Moreover, increased use of fertilizer may lead to health problems apart from the degradation of soil properties as well as soil erosion. The huge increase of population in different developing countries compelled to take necessary steps to increase crop productivity by alternate means. In addition, the nitrogenous compounds used as fertilizers are rather expensive and in many instances beyond the reach of poor farmers. Use of composite biofertilizers can increase fertility status of the soil; it also imparts crop management and the addition of the major nutrients for the plants.

During the present study, the effect of inoculation on the plant biomass accumulation, nodulation, plant height attained have been compared with the application of urea fertilizer. The effect of urea application and inoculation on the nodule initiation, biomass accumulation and the ratio between dry matter production in inoculated and urea applied plants of Mucuna pruriens have been evaluated.

\section{Materials and methods}

Seeds of Mucuna pruriens were collected from the wildly growing plants during the months of January/February from sal forest at the foothills of Sunsary district in eastern Nepal. Morphologically healthy-looking seeds were selected and were sterilized according to Vincent (1970). The sterilized seeds were soaked in sterile water overnight and grown in the field plots of $1 \mathrm{~m}^{2}$ area. Two sets of seeds: a. inoculated and b. un-inoculated were sown in different plots.

The bacterial isolate used for the present study was Rhizobium meliloti MPR-8 isolated locally from Mucuna plants. The test strain MPR-8 was grown in YM broth (Vincent, 1970) in a thermostatic shaker at $28 \pm 1^{\circ} \mathrm{C}$. Broth culture with $2.5 \times 10^{8}$ cells $\mathrm{ml}^{-1}$ was used as inoculants. Adequate amount of inoculum was added with wood charcoal powder as the adsorbant and gum Arabic $(1.5 \%)$ as a sticker to impregnate the seeds. Methods used for seed inoculation was followed according to Somasegaran and Hoven (1985). The inoculated seeds were analyzed for the cfu (colony forming unit) count of rhizobial cells on the seed surface by dilution plate technique.

Field experiment was done taking 4 different treatment conditions as according to Brockwell (1980). Fertilizer urea $80 \mathrm{~kg} / \mathrm{ha}$ was used for applied nitrogen treatment. The treatment conditions are as follows:

$\mathrm{Rh}^{+} \mathrm{N}^{-}$(Inoculated seeds without applied chemical nitrogen)

$\mathrm{Rh}^{-} \mathrm{N}^{+}$(Un-inoculated seeds with applied chemical nitrogen)

$\mathrm{Rh}^{+} \mathrm{N}^{+}$(Inoculated seeds with applied chemical nitrogen)

$\mathrm{Rh}^{-} \mathrm{N}^{-}$(Un-inoculated seeds without applied chemical nitrogen)

Plants were grown for a total period of 50 days. Two plants from each treatment condition were uprooted very carefully after every 10 days and the parameters like biomass, nodulation and symbiotic effectiveness were analyzed.

\section{Results and discussion}

For the improvement of soil quality by legume cultivation it is necessary that there should be the presence of compatible population of rhizobia in the soil. All soils may not have a native population of effective rhizobial strains and therefore, tested strains of the inocula were used to inoculate legume seeds to get desirable response in the enrichment of soil nitrogen.

The total biomass in inoculated without chemical nitrogen $\left(\mathrm{Rh}^{+} \mathrm{N}^{-}\right)$and un-inoculated with urea $\left(\mathrm{Rh}^{-} \mathrm{N}^{+}\right)$treatments were found almost 
similar impacts (Fig. 1). Similar results were obtained by Clayton et al. (2004). Seneviratne et al. (2000) and Tahir et al. (2009) reported that both fertilizer application and inoculation increased plant growth and seed yield as compared to control. Cruz et al. (1997) found that mineral nitrogen addition is not required if the soybean plants are inoculated with proper rhizobia for dry matter production. The maximum plant biomass was accumulated on the $40^{\text {th }}$ days of growth. The sequence of treatment at the maximum biomass accumulation was found in the order of $\mathrm{Rh}^{+} \mathrm{N}^{-}=\mathrm{Rh}^{-} \mathrm{N}^{+}>\mathrm{Rh}^{+} \mathrm{N}^{+}>\mathrm{Rh}^{-}$ $\mathrm{N}^{-}(\mathrm{LSD}=2.46 ; \mathrm{P}>0.05)$.

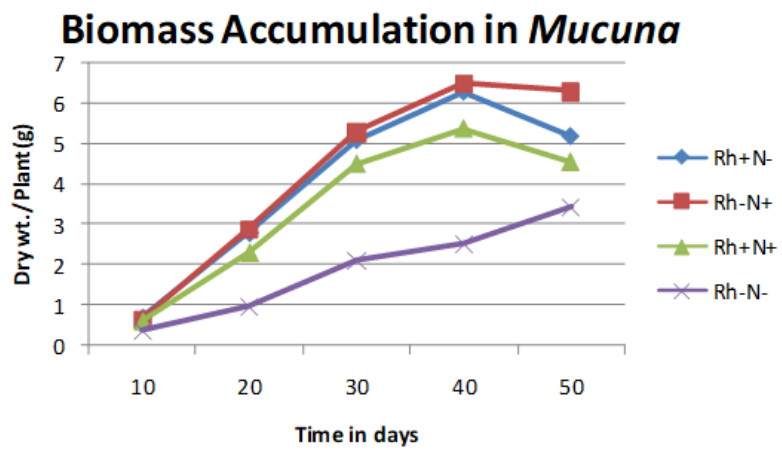

Figure 1. Biomass production of four treatment conditions in Mucuna pruriens

The nodulation in Mucuna in different treatment conditions indicated that the soil condition was poor in specific and native rhizobial population showing no nodulation under controlled conditions $\left(\mathrm{Rh}^{-} \mathrm{N}^{-}\right)$(Fig. 2). Nitrogen application in the form of urea resulted into the suppression of nodulation while under similar situation with no applied nitrogen but with rhizobial inoculation gave highest score of effective nodules. Adeyeye et al. (2017) noticed that the use of fertilizers provided sufficient nitrogen which played a role in antagonistic effect for rhizobial population to form the nodules and nitrogen fixation. Similar results were also obtained by Hoque (1993), Abdel Wahab et al. (1996), Aslam et al. (2000), Li et al. (2009), and Xia et al. (2017). Hoque, reported that the inoculation treatments with Bradyrhizobium markedly increased nodule number, nodule mass, shoot weight and yield of the crop as compared to un-inoculated control and chemical nitrogen (urea) treatment. In his experiment it has been found that inoculation increased yield $113 \%$ over control and $49 \%$ over the urea treatment. However, in our experiment the yield was increased by $150 \%$ on inoculation and $157 \%$ over the urea treatment as compared to control. Various workers (Vincent, 1974; Islam et al., 1987; Hoque et al., 1988) have reported similar beneficial effects of inoculation with Rhizobium and Bradyrhizobium on legume crops.

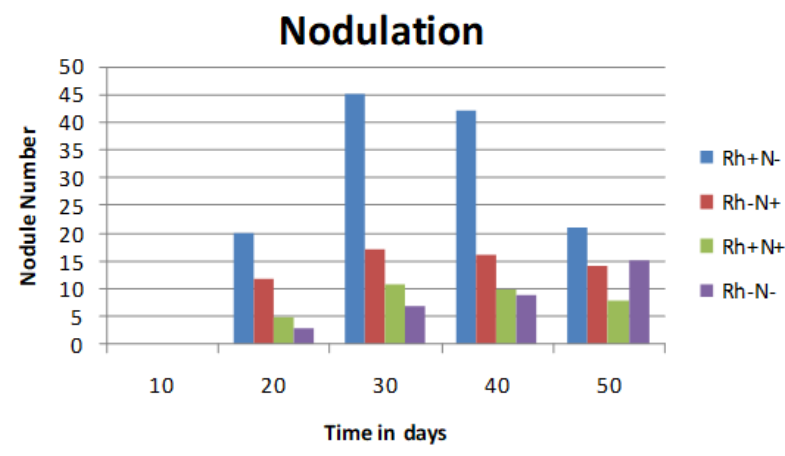

Figure 2. Nodulation in Mucuna pruriens in different treatment conditions

Plant biomass ratio of $\mathrm{Rh}^{+} \mathrm{N}^{-}: \mathrm{Rh}^{-} \mathrm{N}^{-}$and $\mathrm{R}^{-}$ $\mathrm{N}^{+}: \mathrm{R}^{-} \mathrm{N}^{-}$were analyzed to derive the comparative assessment of rhizobial inoculation and applied nitrogen (Fig. 3). Interestingly, the effectiveness of biomass accumulation was found to be similar in both the treatments $(P>0.05)$. It has been reported that the nitrogen application reduced the nodule number and mass of the glycine max and Phaseolus vulgaris (Abaidoo et al., 1990; Aslam et al., 2000; Muniz et al., 2017). Application of urea $(90 \mathrm{~kg} / \mathrm{ha})$ to soybean plants suppressed nodulation by curtailing the enrichment of Bradyrhizobium species on the host plant (Thies et al., 1995). Belanger and Richards (2000) observed that the application of nitrogen fertilizer increased the shoot nitrogen concentration. Chase et al. (1975) also achieved similar results.

\section{Symbiotic Effectiveness}

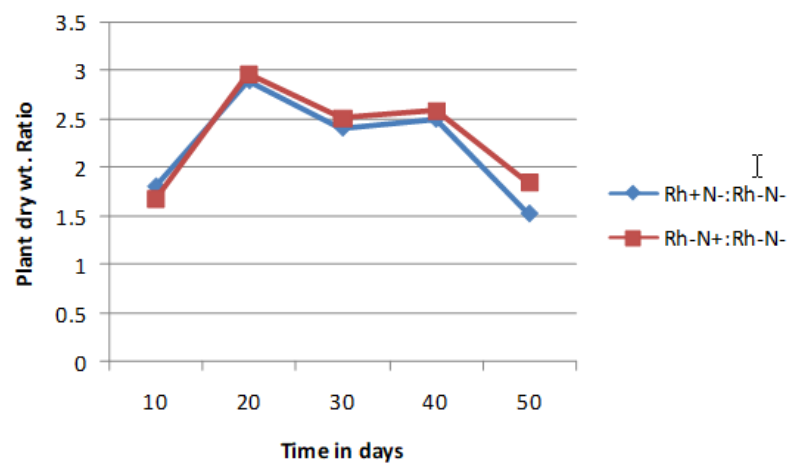

Figure 3. Symbiotic effectiveness of inoculants MPR-8. 
Thus, this study concluded that Mucuna pruriens essentially requires rhizobial inoculation in the soils. Inoculant Rhizobium (MPR8 ), showed adequate nodulation and affect soil nitrogen fertility equal to the application of $80 \mathrm{~kg}$ urea/ha as has been shown by the biomass accumulation. In terms of biomass productivity inoculation or urea application gave almost similar results. So, the use of inoculation practice is far better in terms of nature conservation and the economic perspectives for the small and developing countries like Nepal.

\section{Acknowledgements}

We are very much thankful to the Department of Botany, Trichandra Multiple College, Ghantaghar, Kathmandu for providing us the essential support for the completion of the study. My colleagues as well as the non-teaching staffs of the department are highly acknowledged.

\section{References}

Abaidoo, R.C., B.B. Bohlool and P.W. Singleton 1990. Influence of elevation and applied nitrogen on rhizosphere colonization and competition for nodule occupancy by different rhizobial strains on field grown soybean and common bean. Can. J. Microbiol. 36: 92-96.

Abdel-Wahab, H.H., H.H. Zahran and M.H. Abd-Alla 1996. Root hair infection and nodulation of four grain legumes as affected by the form and the application time of nitrogen fertilizer. Folia Microbiol. 41: 303-308.

Adeyeye, A.S., A.O. Togun, A.B. Olanigan and W.B. Akanbi 2017. Effect of fertilizer and Rhizobium inoculation on Growth and Yield of Soybean Variety (Glycine max L. Merril). Adv. Crop Sci. Tech. 5: 2-9.

Arreseigor, C., F.R. Minchin, A.J. Gordon and A.K. Nath 1997. Possible cause of physiological decline in soybean nitrogen fixation in response to nitrate. J. Exp. Bot. 48: 905-913.

Aslam, M., I. A. Mahmood, T. Sultan and S. Ahmed 2000. Inoculation approach to legume crops and their production assessment in Pakistan-A review. Pakistan Journal of Biological Sciences 3(2): 193195.

Atkins, C.A., B.J. Shelp, J. Kuo, M.B. Peoples and T.S. Pate 1984. Nitrogen nutrition and the development and sequence of nodules on cowpea seedlings. Planta 162: 316-326.

Belanger, G. and J.E. Richards 2000. Dynamics of biomass and $\mathrm{N}$ accumulation of alfalfa under three nitrogen fertilization rates. Plant and Soil 219: 177-185.

Brockwell, J. 1980. Experiments with crop and pasteur legume-principles and practices. In
Methods for evaluating biological nitrogen fixation. John Wiley and Sons, New York.

Chase, L.E., T.A. Long, J.B. Washiko and B.R. Baumgardt 1975. Effect of $\mathrm{N}$ fertilization on constituents of alfalfa. J. Diary Sci. 59: 170-174.

Clayton, G.W., W.A. Rice, N.Z. Lupwayi, A.M. Jonston, G.P. Lafond, C.A. Grant and F. Walley 2004. Inoculant formulation and fertilizer nitrogen effects on field pea: Nodulation, $\mathrm{N}_{2}$ fixation and nitrogen partitioning. Canadian Journal of Plant Science 84(1): 79-88.

Cruz, G.N., M.P. Stampford, J.A.A. Silva and M. Chamber-Prez 1997. Effect of inoculation with Bradyrhizobium and urea application on nitrogen fixation and growth of Yam Bean (Pachyrhizus erosus) as affected by phosphorus fertilizers in an acid soils. Tropical Grassland 31: 538-542.

Davidson, I.A. and M.J. Robson 1986. Effects of contrasting patterns of nitrate uptake, $\mathrm{N}_{2}$ fixation, nodulation and growth of white clover. Ann. Bot. 57: 331-338.

Eaglesham, A.R.J. 1989. Nitrate inhibition of root nodule symbiosis in doubly rooted soybean plants. Plants Crop Sci. 29: 115-119.

Herdina, J.H. and J.H. Silsbury 1989. Nodulation and early growth of faba bean (Vicia faba L) and pea (Pisum sativum L) as affected by strains of Rhizobium $\mathrm{NO}_{3}$ supply and growth temperature. Aust. J. Agric. Res. 40: 991-1001.

Hoque, M.S. 1993. Bradyrhizobium technology: a promising substitute for chemical nitrogen fertilizer in Bangladesh agriculture. Plant and Soil 155/156: 337-340.

Hoque, M.S., M. Jahiruddin and G.C. Paul 1988. Response of soybean to Rhizobium inoculation and NPK fertilization. Crop Research 1: 102-108.

Islam, A.B. M.S. Hoque and J.H. Bhuiya 1987. Effect of different Rhizobium inoculants on soybean. Bangladesh J. Agric. 12: 129-137.

Ismande, J. 1986. Inhibition of root nodule development in soybean by nitrate or reduced nitrogen. J. Exp. Bot. 37: 348-355.

Li, Y.Y., C.B. Yu, X. Cheng, C.J. Li, J.H. Sun, F.S. Zhang, H. Lambers and L. Li 2009. Intercropping alleviates the inhibitory effects on $\mathrm{N}$ fertilization on nodulation and symbiotic $\mathrm{N}_{2}$ fixation of faba beans. Plant and Soil 323: 295-308.

Muniz, A.W., M.D. Costa, E.L. Sarcol de sa, A.B. Fiuza and E. Brose 2017. Symbiotic efficiency of Pea (Pisum sativum) rhizobia associated under field conditions. Afr. J Agric. Res. 12(32): 25822585.

Purcell, L.C. and T.R. Sinclair 1990. Nitrogenase activity and nodule gas permeability response to rhizospheric $\mathrm{NH}_{3}$ in Soybean. Plant Physiol. 92: 268-272.

Sanginga, N., B. Ibewiro, P. Houngnandan, B. Vahlauwe, J.A. Okokun, I.A. Akobundu and M. Verdteeg 1996. Evaluation of symbiotic properties and nitrogen contribution of Mucuna to maize 
grown in the derived Savanna of West Africa. Plant and Soil 179: 119-129.

Seneviratne, G., L.H.J. Van-Holm and E. Ekanayake 2000. Agronomic benefits of rhizobial inoculants use over nitrogen fertilizer application in tropical soybean. Field Crop Research 68: 199-203.

Somasegaran, P. and H. Hoven 1985. Methods in Legume-Rhizobium technology. University of Hawaii (NifTAL project and MIRCEN).

Somasegaran, P., H. Hoven, and J.C. Burton 1992. A medium scale fermentor for mass culture of rhizobia. World J. Microbiol. Biotechnol. 8: 6873.

Tahir, M.M., M. Kzleem Abbasi, Nasir Rahim, Abdul Khaliq and Mustaq Hussain Kazmi 2009. Effect of Rhizobium inoculation and NP fertilization on growth, yield and nodulation of soybean (Glycine $\max \mathrm{L}$ ) in sub-humid hilly region of Rawalkot Azad Jammu and Kashmir, Pakistan. Afr. J.
Biotechnol. 8(22): 6191-6200.

Thies, J.E., P.L. Woomer and P.W. Singleton 1995. Enrichment of Bradyrhizobium sp. populations in soils due to cropping of the homologous host legume. Soil Biol. Biochem. 27: 633-636.

Tian, G., G.O. Kolawole, B.T. Kang and G. Kirchhof 2000. Nitrogen fertilizer replacement indexes of legume cover crops in the derived Savanna of West Africa. Plant and Soil 224: 287-296.

Vincent, J.M. 1970. A manual for the practical study of the root nodule bacteria. IBP Handbook 15, Blackwell, Oxford.

Vincent, J.M. 1974. The biology of nitrogen fixation (Quispel Amer, A. Ed.), Elsevier Pub. Co., N.Y.

Xia, X., C. Ma, S. Dong, Y. Xu and Z. Gong 2017. Effects of nitrogen concentration on nodulation and nitrogenase activity in dual root systems of soybean plants. J. Soil Science \& Plant Nutrition 63:470-482. 